\title{
Sentimentos maternos durante o puerpério: uma revisão da literatura
}

\author{
Maternal feelings during the puerperium: a literature review \\ Sentimientos maternos durante el puerperio: una revisión de la literatura
}

Michael Douglas Sousa Leite

ORCID: https://orcid.org/0000-0002-9356-1872

Faculdade Católica Santa Teresinha, Brasil

E-mail: michaeldouglas_adm@hotmail.com

Ankilma do Nascimento Andrade Feitosa

ORCID: https://orcid.org/0000-0002-4751-2404

Faculdade Santa Maria, Brasil

E-mail: ankilmar@hotmail.com

Kylvia Luciana Pereira Costa

ORCID: https://orcid.org/0000-0001-9441-6135

Universidade Federal de Campina Grande, Brasil

E-mail: kylvinha_cz@hotmail.com

Luciana Modesto de Brito

ORCID: https://orcid.org/0000-0003-1050-0239

Faculdade Santa Maria, Brasi

E-mail: lucianamodesto@hotmail.com

Anilton Jorge da Nóbrega Gonçalves

ORCID: https://orcid.org/0000-0001-7608-8895

Faculdade Santa Maria, Brasil

E-mail: aniltonjorge@hotmail.com

Robson Leite Sampaio

ORCID: https://orcid.org/0000-0002-4414-292X

Faculdade Santa Maria, Brasil

E-mail: robsom mea@hotmail.com

Thalita Sévia Soares de Almeida Magalhães

ORCID: https://orcid.org/0000-0001-8977-1650

Faculdades Integradas do Ceará, Brasil

E-mail: thalitasevia22@gmail.com

Daniel Moura Gouveia

ORCID: https://orcid.org/0000-0002-7551-4271

Universidade Federal de Campina Grande, Brasil

E-mail: danielmouragouveia@gmail.com

Agilio Tomaz Marques

ORCID: https://orcid.org/0000-0001-8364-5063

Universidade Federal de Campina Grande, Brasil

E-mail: agiliotomaz@hotmail.com

Kévia Katiúcia Santos Bezerra

ORCID: https://orcid.org/0000-0002-2310-0034

Universidade Federal de Campina Grande, Brasil E-mail: keviabezerra@gmail.com

Helmo Robério Ferreira de Meneses ORCID: https://orcid.org/0000-0001-9326-8548

Faculdades Integradas do Ceará, Brasil E-mail: helmo_rob@hotmail.com

Thaise de Abreu Brasileiro Sarmento ORCID: https://orcid.org/0000-0003-0390-805X

Universidade Federal de Campina Grande, Brasil E-mail: thaiseabreu@hotmail.com

Glauber Iure Cardoso de Menezes Silva ORCID: https://orcid.org/0000-0002-8483-4488 Faculdades Integradas do Ceará, Brasil E-mail: glauber.adv@bol.com.br

Marciana Gomes de Araújo e Sousa ORCID: https://orcid.org/0000-0001-6591-7758 Faculdades Integradas de Patos, Brasil E-mail: rhanna_love@hotmail.com

Benigna Catarina de Belchior Pires ORCID: https://orcid.org/0000-0002-7557-5103

Universidade Regional do Cariri, Brasil E-mail: benignacatarina@gmail.com 


\title{
Wanessa Arnaud Moura \\ ORCID: https://orcid.org/0000-0003-0274-5527 Universidade Federal de Campina Grande, Brasil E-mail: wanessa_arnaud@hotmail.com \\ Jefferson Thiago da Silva Victor \\ ORCID: https://orcid.org/0000-0002-8867-9032 Faculdades Integradas do Ceará, Brasil E-mail: jeffersonethiane10@gmail.com \\ Georgy Xavier de Lima Souza \\ ORCID: https://orcid.org/0000-0001-8971-578X Faculdades Integradas do Ceará, Brasil E-mail: georgyxavier@bol.com.br \\ Júlia Marcia Lourenço de Almeida Martins Medeiros ORCID: https://orcid.org/0000-0001-8554-8136 Universidade Federal de Campina Grande, Brasil E-mail: juliaalmeidamartins@gmail.com
}

\begin{abstract}
Resumo
A gestação e o puerpério consistem em uma fase da vida da mulher marcada por uma série de alterações fisiológicas, sociais, familiares e psicológicas que desencadeiam manifestações de sentimentos ambíguos que podem provocar desequilíbrio psicológico nas mulheres e, consequentemente, na sua interação com o bebê. Neste período, a mulher se encontra mais suscetível ao aparecimento de problemas mentais quando comparado a outras fases da vida, pois as suas defesas físicas e psicossociais encontram-se direcionadas à proteção e vulnerabilidade do bebê. Nesse sentido, o presente trabalho busca caracterizar a prevalência e os fatores associados aos sentimentos pós-parto em puérperas. Para tanto, a presente pesquisa trata-se de uma revisão integrativa da literatura, utilizando artigos, livros, manuais, monografias, dissertações e teses. $\mathrm{O}$ estudo possibilitou verificar que as mulheres vivenciam uma série de mudanças no período do puerpério, desde a considerável diminuição das horas de sono, até a perda de sua autonomia, uma vez que toda a sua rotina é controlada de acordo com os horários do bebê. Esse período traz uma série de sentimentos novos, que passam a participar de suas tomadas de decisão, daquele momento em diante. Conclui-se que esse estudo apresentou como relevância o conhecimento sobre a vivência da mulher contemporânea diante da maternidade e como ela passa a definir a sua representação, pois foi constatado que apesar de tantos papeis importantes na sociedade, além de o de ser mãe, a maternidade continua sendo para a mulher um acontecimento de grande, senão o de maior importância em sua vida.
\end{abstract}

Palavras-chave: Depressão Pós-parto; Mulheres; Puerpério; Sentimentos.

\begin{abstract}
Pregnancy and puerperium are a phase of a woman's life marked by a series of physiological, social, family and psychological changes that trigger manifestations of ambiguous feelings that can cause psychological imbalance in women and, consequently, in their interaction with the baby. During this period, women are more susceptible to the onset of mental problems when compared to other stages of life, as their physical and psychosocial defenses are directed towards the protection and vulnerability of the baby. In this sense, this study seeks to characterize the prevalence and factors associated with postpartum feelings in postpartum women. Therefore, this research is an integrative literature review, using articles, books, manuals, monographs, dissertations and theses. The study made it possible to verify that women experience a series of changes in the postpartum period, from the considerable reduction in sleep hours to the loss of their autonomy, since their entire routine is controlled according to the baby's schedule. This period brings a series of new feelings, which start to participate in their decision-making, from that moment onwards. It is concluded that this study presented as relevance the knowledge about the experience of contemporary women in face of motherhood and how she begins to define its representation, as it was found that despite so many important roles in society, in addition to being a mother, Motherhood continues to be a major event for women, if not the most important in their lives.
\end{abstract}

Keywords: Baby blues; Women; Puerperium; Feelings.

\section{Resumen}

El embarazo y el puerperio son una fase de la vida de la mujer marcada por una serie de cambios fisiológicos, sociales, familiares y psicológicos que desencadenan manifestaciones de sentimientos ambiguos que pueden provocar un desequilibrio psicológico en la mujer y, en consecuencia, en su interacción con el bebé. Durante este período, las mujeres son más susceptibles a la aparición de problemas mentales en comparación con otras etapas de la vida, ya que sus defensas físicas y psicosociales están dirigidas a la protección y vulnerabilidad del bebé. En este sentido, este estudio busca caracterizar la prevalencia y los factores asociados a los sentimientos posparto en mujeres posparto. Por tanto, esta investigación es una revisión integradora de la literatura, utilizando artículos, libros, manuales, monografías, disertaciones y tesis. El estudio permitió constatar que las mujeres experimentan una serie de cambios en el posparto, desde la reducción considerable de las horas de sueño hasta la pérdida de su autonomía, ya que toda su rutina está controlada según el horario del bebé. Este período trae una serie de nuevos sentimientos, que comienzan a participar en su toma de decisiones, a partir de ese momento. Se concluye que este estudio presentó como relevancia el conocimiento 
sobre la experiencia de la mujer contemporánea frente a la maternidad y cómo ella comienza a definir su representación, pues se encontró que a pesar de tantos roles importantes en la sociedad, además de ser madre, La maternidad sigue siendo un acontecimiento importante para las mujeres, si no el más importante en sus vidas.

Palabras clave: Baby blues; Mujeres; Puerperio; Sentimientos.

\section{Introdução}

O período gestacional consiste em um período da vida em que a mulher imagina e planeja uma série de momentos que vivenciará junto ao seu filho. O nascimento do bebê, aliado ao período de sua gestação, estão caracterizados pelas mudanças fisiológicas, sociais, familiares e psicológicas, marcado pelo surgimento de sentimentos ambivalentes que podem refletir diretamente na saúde mental das mulheres (Fernandes \& Cotrin, 2013).

Tolentino; Maximino \& Souto (2016) acrescentam que, durante a gestação, as alterações acima citadas encontram-se mais acentuadas, de modo que a gestante poderá ter sensações de mutilação do seu corpo como resposta ao fenômeno da gravidez. Para Fernandes \& Cotrin (2013), no momento imediato e subsequente ao parto, conhecido como puerpério, a mulher está com as suas emoções mais sensibilizadas e, portanto, estão mais sujeitas a desencadear patologias de cunho psicológico quando comparado a outras fases da vida, pois as suas defesas físicas e psicossociais encontram-se direcionadas à proteção e vulnerabilidade do bebê. Acrescente-se que, o pós-parto é uma etapa crítica para a mulher devido às violentas mudanças nas taxas hormonais, para além de todo o estresse que o parto e as novas rotinas implicam a nível biológico e emocional. Nessa fase, a sensação de vazio e solidão pode ser aflorada (Alves; Lovadini \& Sakamoto, 2021).

As psicoses que se desenvolvem no puerpério ocorrem em uma dimensão de 1 a 2 casos para cada 1.000 mulheres. Nestes casos, a mulher apresenta sintomas acentuados, como os sentimentos ambivalentes, extremistas (ora alegre, ora deprimida), fantasias e ideação persecutória, mudança de pensamento, deprimida, pensamentos de morte (homicídio ou suicídio) O surgimento de sentimentos como foram citados, merecem atenção especial a fim de evitar o surgimento de síndromes como a depressão pós-parto, psicose puerperal ou baby blues. Estes, em grande parte dos casos, requerem tratamento intensivo, ocorrendo em muitos casos, necessidade de internação ainda nas duas primeiras semanas sequenciais ao parto (Mastellin \& Silva, 2012; Freitas, 2021).

A depressão, de acordo com Mastellin \& Silva (2012), pode significar desde um estado afetivo normal, quanto um sintoma, síndrome ou doença. Geralmente, está associada a reações normais frente à exposição a determinados sofrimentos e crises de ausência inevitáveis pela perda durante o ciclo de vida do indivíduo; ou ainda assim, a uma síndrome ou doença que inclui mudanças de temperamento, psíquicas, psicológicas e comportamentais.

No Brasil, a depressão chega a atingir de $2 \%$ a $5 \%$ da população, com predomínio no sexo feminino, atrelados principalmente a ocasiões como a gestação, o parto e o período pós-parto. Dessa forma, associado ao nascimento de um bebê, está referido como um agrupamento de manifestações sintomatológicas que circundam o período entre a quarta e a oitava semana subsequente ao parto, acometendo cerca de $10 \%$ a $12 \%$ das mulheres parturientes. Dentre a sintomatologia está a irritabilidade, o choro frequente, desequilíbrio emocional marcado pela sensação de abandono e pela falta de força, perspectivas, diminuição significativa da libido, inapetência e comprometimento dos padrões de sono. Ou seja, neste tipo de patologia, as pacientes são incapazes de concretizar as atividades de vida diária, ou seja, é uma condição que interfere substancialmente o funcionamento da mulher (Ryung et al., 2011).

Por outro lado, Jericó \& Teixeira (2012) sugerem que os sintomas da Depressão Pós-Parto (DPP), podem não surgir nas primeiras semanas após o nascimento do bebê, mas também pode manifestar-se em alguma outra ocasião até que o bebê complete 12 meses de vida.

Nesse contexto, é importante que a gestante seja informada, durante o pré-natal, sobre o risco potencial que ela tem de desenvolver alterações de humor logo após o parto, atentando para o fato de quando a sintomatologia persistir por mais de duas 
semanas, seja necessário recorrer ao atendimento médico.

Tendo em vista a problemática, a investigação em questão, reveste-se de importância, porque em decorrência de posse dos resultados, será possível uma melhor compreensão da dinâmica deste fenômeno que atinge a um número considerável de mulheres após o nascimento de seus filhos pelos profissionais de saúde que são responsáveis pela assistência à mulher em todo seu ciclo gravídico-puerperal, ademais, almeja-se contribuir na implementação das atividades relativas à promoção, prevenção e tratamento da saúde mental feminina para os casos de suscetibilidade.

A escolha da temática aqui abordada é justificada pela a importância crescente ao assunto, e constatando também o prejuízo que esse processo de desequilíbrio psicológico pode provocar não só à saúde da mãe, mas também ao desenvolvimento do feto, interferindo substancialmente na condução de sua vida e de toda família.

\section{Metodologia}

Para alcance dos objetivos foi utilizado uma revisão integrativa da literatura, cuja elaboração compreende seis etapas: seleção das hipóteses ou questões para revisão; determinação dos critérios para seleção da amostra; definição das características da pesquisa original; análise dos dados; interpretação dos resultados e apresentação da revisão (Mendes; Silveira; Galvão, 2008).

A pesquisa foi construída com base nesta problemática: quais os principais sentimentos vivenciados pelas mulheres no período puerpério?

Para levantamento dos artigos e trabalhos foram utilizadas as seguintes bases: LILACS, Medline, Scielo, Bdenf e Google Acadêmico, além de livros, manuais, monografias, dissertações e teses. Os descritores usados foram "Sentimentos", "Puerpério" e "Mulheres". A princípio, a busca pelos descritores foi dada individualmente, utilizando-se posteriormente os cruzamentos utilizando o operador booleano "and". Ainda assim, para a seleção da amostra, foram válidos os seguintes critérios de inclusão: artigos publicados nos idiomas inglês e português, no período de 2010 a 2021, sendo selecionado 22 trabalhos que retrataram a temática em estudo.

Os resultados foram divididos em dois tópicos onde o primeiro abordou a Contextualização sobre o Puerpério e o segundo sobre os Sentimentos Vivenciados pela Mulher no Período Puerperal.

\section{Contextualização sobre o Puerpério}

De acordo com Amorin (2010), o termo puerpério tem origem no latim "puer" e "parere", traduzido por criança e parir, respectivamente. Do ponto de vista orgânico, trata-se de um momento que tem início no nascimento de uma criança com a placenta expelida, até a restauração do aparelho reprodutor ao seu estado fisiológico sem gravidez. Para tanto, estima-se que a sua duração tenha de seis a oito semanas. Conhecido ainda como sobreparto ou pós-parto, pode ser chamado também de quarto trimestre da gestação, pois é neste período que ocorre a involução do sistema reprodutor feminino ao seu estado fisiológico (Moreira, 2015). Ele pode ser dividido em três fases segundo a maioria dos autores da área: imediato são as primeiras quatro horas ocorridas após o nascimento; mediato, que vai do fim do período imediato até terceiro dia; e tardio que vai do período mediato até sexta ou oitava semana (Lermen, 2010).

O puerpério para a mulher representa um grande momento na sua vida, são períodos de grandes transformações, no seu organismo, no seu psicológico e no papel sociofamiliar, onde as primeiras semanas podem ser permeadas por cansaço e dor à medida que seu corpo se recuperara após o parto (Siqueira et al., 2017). O fenômeno do nascimento representa para a mulher uma experiência marcada por sentimentos ambíguos e extremos, que varia desde a alegria ao estado deprimido que este, por sua vez, está marcado pelo desequilíbrio emocional e pelo risco de a mulher desenvolver síndromes psiquiátricas no pós-parto (Villela et al., 2016). 
Para se ter uma ideia, segundo os argumentos do autor citado acima, oito de cada dez mulheres podem ter o que chamamos de melancolia da maternidade, que representa uma alteração passageira do humor caracterizado pela instabilidade psíquica e emocional, pelo comprometimento dos padrões do sono durante um período de até duas semanas após o parto. Entre os transtornos psíquicos do puerpério predomina as doenças afetivas, sendo a Depressão Pós-Parto a mais frequente.

Com propriedade, Sobreira \& Pessôa (2012), relatam que as alterações desse período podem ocorrer em virtude do desequilíbrio hormonal, do processo de amamentação, da adaptação psicológica da mãe e da relação de vínculos mãe/filho e familiares. Ressalta ainda que, isso pode ocorrer como resultado da inexperiência do cuidado com o bebê, pela mudança do cotidiano da casa, pela relação entre os pais e o filho, bem como o desgaste dos vínculos familiares.

Fortalecendo as ideias acima, Gonçalves (2012), supõe também a existência de outros fatores tais como as frustrações e a monotonia do período de internação e a passagem da situação de espera ansiosa típica do final da gravidez para a de conscientização da nova realidade que, ao lado da satisfação da maternidade, significa também a responsabilidade de assumir novas tarefas e a limitação de algumas atividades anteriores.

Sendo considerado um período de mudanças na vida, seja ela de qualquer raça, cor e religião, pois esta é vista como um período de expectativa e de modificações profundas e inter-relacionadas no equilíbrio fisiológico e psicológico individual e nas associações interpessoais. Essas mulheres apresentam ainda comportamentos regressivos: são exigentes, não cooperadoras, provocativas, agressivas, indiferente, controladoras ou desinteressadas dos cuidados médicos (Moreira, 2015). Refere ainda que, se a instabilidade emocional não for controlada poderá levar a mulher a complicações psicológicos da gravidez para o pós-parto, e consequentemente podendo pôr em risco também o desenvolvimento emocional da criança, o que seria a maior consequência (Alves; Lovadini \& Sakamoto, 2021).

A primeira aflição que surge na puérpera, conforme o autor acima mencionado é o aleitamento materno, questionandose se terá leite para a amamentação, isso se torna um dos maiores medos que é a possibilidade de fracassar como mãe. Já que todas as mães sabem que o leite materno é saudável e adequado para o bebê, que não vai necessitar de outro alimento até os seis meses de idade. Depois dessa idade o leite deve ser mantido, mais acompanhado de outros alimentos do cotidiano familiar, que será indispensável para a criança. Somando-se a isso, tem-se a percepção de que quando a mulher deseja ter um filho, supõe que ela não apenas deseje renunciar a um lugar somente de filha, mas implicam outras questões: mudanças de um corpo de menina, transformando o seu corpo em uma mulher grávida, onde ocorrem grandes transformações (Moreira, 2015).

Na prática assistencial deve-se implementar alguns elementos subjetivos do cuidado interativo, como dar atenção, demonstrar paciência, dar apoio físico e emocional e conversar com estas mulheres, visando a adaptação maternas às situações transitórias do pós-parto, a partir da ajuda para se sentirem tranquilas no desempenho da maternidade. Em suma, durante a gestação deve preparar-se mentalmente para as diversas alterações no estilo de vida, que logo ocorrerão. Buscar auxílio para as tarefas domésticas e com o bebê durante a primeira semana, escolher um cuidador infantil de forma que possa ter um descanso0 regular, e decidir com antecedência o que precisará quando o bebê chegar. Promoção do bem estar físico e emocional e adaptação ao aleitamento materno, a interação com os familiares e as informações quanto à continuidade dos cuidados em domicílio (Alves; Lovadini \& Sakamoto, 2021).

\section{Sentimentos Vivenciados pela Mulher no Período Puerperal}

As alterações desse período podem ocorrer em virtude do desequilíbrio hormonal, do processo de amamentação, da adaptação psicológica da mãe e da relação de vínculos mãe/filho e familiares. Sobreira \& Pessôa (2012), relatam que isso pode ocorrer como resultado da inexperiência do cuidado com o bebê, pela mudança do cotidiano da casa, pela relação entre os pais e o filho, bem como o desgaste dos vínculos familiares. Diante disso, está justificado o porquê de o puerpério consistir em um 
período de grandes alterações no qual a mulher está mais sujeita ao desenvolvimento de alterações de humor e ao surgimento de perturbações de natureza psíquica.

Sobre isso, Sobreira \& Pessôa (2012), explica que a mãe quando confrontada com a necessidade de adaptação às novas mudanças, tornam-se mais suscetíveis a atravessar um processo de desequilíbrio psicológico. Essas transformações, segundo Gonçalves (2012), podem somar-se a outros eventos adversos, de origem biológica, física e psicossocial e conduzir o indivíduo ao desenvolvimento de doenças psiquiátricas. A adaptação a estas mudanças tão intensas leva a mulher a tornar-se sensível, confusa e ansiosa, associada a uma instabilidade emocional característica da primeira semana pós-parto (Amorin, 2010).

Vale destacar que, nesse processo, surgem alguns obstáculos que mascaram o diagnóstico da mulher com transtornos emocionais pós-parto como, por exemplo, a presença do profissional de saúde durante o período de institucionalização dessa mulher, que tem maior experiência, que cuida e no, entanto, ao se dirigir ao domicílio não existe essa figura e os medos e anseios acabam surgindo, além de aparecer os sentimentos de solidão, desamparo e fadiga (Lermen, 2010; Siqueira et al., 2017).

Para Amorin (2010), a transição da fase de dependência para a fase de independência precisa ser bem assistida, a fim de evitar momentos de stress à nova mãe e família. Isto se deve em parte, ao curto espaço de tempo de internamento. A mulher, muitas vezes, não consegue sair da fase de dependência para uma fase de independência de forma a cuidar da sua própria saúde e do seu filho. Para além de que, quando se trata do nascimento do primeiro filho, o processo de transição para a parentalidade, com as alterações nos papéis familiares e o aumento da responsabilidade implica muitas vezes momentos de stress à "nova" mãe e família.

\subsection{Formação de Laços afetivos}

O desejo da mulher de ter um filho pode vir de inúmeros motivos diferentes. A mulher ainda criança aprende a se comportar conforme as figuras maternas que a rodeiam e frequentemente é reforçada por isso. Por volta do primeiro e segundo ano de vida a menina cuida de sua boneca como sua mãe fizera com ela e o desejo de ser mãe pode vir desde essa época. Pode vir também, com o propósito de que a criança realize oportunidades perdidas pelos pais e ela passa a ter a obrigação de cumprilas. Essa busca pela perfeição tende a trazer frustrações para os pais e interferir na interação pais/ bebê. A mulher pode de sejar ter um filho na esperança de renovação de antigos laços afetivos, que permaneciam de alguma forma em estados latentes (Freitas, 2021).

A formação dos laços afetivos mãe/bebê não ocorre automaticamente. O que não significa que, se em um momento inicial os pais tiverem dificuldades com seu bebê, eles nunca formarão um bom laço afetivo. Comumente, os pais se sentem culpados por não conseguirem desenvolver os laços afetivos por seu filho de imediato, e neste momento, o psicólogo é importante, ajudando os pais a alcançarem mais proximidade com a criança (Dias, 2014). Winnicott (2013), em suas observações destaca o vínculo como um processo contínuo que não acontece da noite para o dia. Nesse sentido, muitos estudos se voltaram para compreender o estabelecimento dos primeiros laços da criança pequena com sua mãe, pois é nesse momento que produzem os alicerces da vida psíquica e da saúde mental.

É através do contato com a criança, trocando-a, dando-lhe banho e amamentando-a, que se constrói um elo de convivência entre a mulher e seu filho. Assim, a criança sente-se segura e passa a ter confiança nos pais, o que faz com que, futuramente, ela desenvolva uma relação de segurança e confiança com as outras pessoas que a rodeiam. Dias (2014), acredita que a forma e a qualidade da relação entre os pais e a criança são bastante influenciadas pela história de vida dos pais e pelas circunstâncias em que ocorre a gravidez.

A formação dos vínculos afetivos entre mãe e bebê se inicia antes mesmo da gravidez. Dá-se início a esse processo a partir do desejo da mulher de ser mãe. Segundo Moraes (2010), as expectativas da mãe ao filho são oriundas do próprio interior, de suas relações pregressas e de suas necessidades com relação ao filho, que ficam armazenadas no inconsciente e subconsciente. 
A mulher já traz seu filho em seu inconsciente, como um bebê fantasmático. Lopes; Prochnow \& Piccinini (2010), consideram que o bebê fantasmático abre o caminho do passado para o bebê real; é o bebê fantasmático que assegura os vínculos entre o bebê real e suas próprias origens. Mas, o alvorecer desta ligação ocorre durante a gestação, onde as representações maternas e paternas começam a acontecer.

Outra forma de representação acerca da criança, os autores supracitados expõem que é o chamado bebê imaginário, é aquele que os pais constroem em sonhos e pensamentos. O mesmo começa a se formar entre o quarto e o sétimo mês de gestação. Mas a partir do sétimo mês, essas representações tendem a suprimir, para dar espaço ao bebê real, de modo a evitar desapontamentos. Este recém-nascido pode ter semelhanças ao imaginário ou exacerbadas divergências, o que pode gerar intensas frustrações nos pais. É sabido que o apego pelo recém-nascido constrói-se com base em relacionamentos preliminares com a criança imaginária e com o feto que durante nove meses foi elemento integrante da vida dos pais (Lopes; Prochnow \& Piccinini, 2010).

Frente às expectativas da mãe em relação a seu bebê, a literatura aponta repercussões tanto positivas, quanto negativas, para a relação entre a díade. Segundo Lopes; Prochnow \& Piccinini (2010), os aspectos positivos envolvem os desejos e fantasias da mãe construída em torno do bebê. Ainda segundo os autores, à medida que a mãe consegue idealizar as suas fantasias em torno do filho, ela se torna capaz de desenvolver um nível de relação mais próximo ao bebê. Por outro lado, Villela et al., (2016), enfatizam que as expectativas são tidas como negativas quando o bebê não é capaz de ter sua própria identidade, quando a mãe não consegue aceitar as diferenças singulares do filho e, consequentemente, acaba abandonando a sua carga de projeções sobre ele.

Winnicott (2013), considera que nos últimos meses de gestação a mulher se prepara para a árdua tarefa de ser mãe. O autor refere-se a esse estado como "preocupação materna primária" e a respeito do tema salienta que:

Neste estado, as mães se tornam capazes de colocar-se no lugar do bebê, por assim dizer. Isto significa que elas desenvolvem uma capacidade surpreendente de identificação com o bebê, o que lhes possibilita ir ao encontro das necessidades básicas do recém-nascido, de forma que nenhuma máquina pode imitar, e que não pode ser ensinada (Winnicott, 2013, p. 54).

Ainda prosseguindo com a opinião do autor mencionado acima o qual afirma que é de grande valia para o desenvolvimento psicoafetivo do bebê a forma como ele é segurado. As três principais funções da mãe são: segurar o bebê, também chamado de holding, manipular o bebê ou handing e apresentar o objeto ao bebê. O fato de segurar e manipular o bebê de forma adequada facilita os processos de maturação. É a partir daí que a criança passa a adquirir confiança no mundo e nas pessoas que a cercam. No holding, além de segurar o bebê, a mãe o retém, o contém, o sustém. E o handing descreve os cuidados de manipulação, o manuseio do bebê. A última função da mãe não menos importante, é a relação objetal é quando a mãe e o bebê chegam a um acordo na situação de alimentação estão lançadas as bases de um relacionamento humano. Muitos bebês, antes de tomar o seio da mãe com o objetivo de suprir a fome, o exploram com a mão, boca e gengiva, até que acorra enfim a amamentação. É a partir daí que se estabelece o padrão da capacidade da criança de relacionar-se com os objetos e com o mundo.

A comunicação entre a mãe e o bebê, também são de imensa relevância para o desenvolvimento dos laços afetivos. Porém, conforme Dias (2014), ao nascer o bebê ainda é desconhecido para os pais. E eles possuem dificuldade em decifrar seus códigos de comunicação, o que torna o primeiro mês, um período de intensa ansiedade. Esta ansiedade diminui, gradativamente, à medida que a criança evolui satisfatoriamente.

De acordo com Winnicott (2013), uma das primeiras formas de comunicação se estabelece através da respiração da mãe, seu calor, seu cheiro, sua voz e até mesmo as batidas de seu coração. A criança reconhece a mãe por meio desses sinais. O embalar também propicia a ocorrência de comunicação entre mãe e filho. A mãe, por sua vez, também passa a reconhecer as 
necessidades do bebê através dos sinais que ele oferece. A maioria delas relata ser capaz de traduzir o choro do seu bebê e as necessidades implícitas por meio deste.

Nessa mesma linha, Marciano \& Amaral (2015), destacam algumas questões importantes como a assistência humanizada, contato precoce entre mãe e bebê, a rede de apoio social e a estabilidade financeira como fatores de promoção do vínculo mãe-bebê. O que ocorre precocemente durante o período do pós-parto pode ajudar, imensamente, no desenvolvimento de um vínculo dos pais com o bebê. Este laço, definido como uma relação singular e duradoura, entre mãe e filho é condição única para que as crianças se transformem em adultos saldáveis e independentes em relação ao seu ambiente.

A ocasião do pós-parto está marcada por um período de novas adaptações e enfrentamento de novos desafios, da ordem fisiológica e psicológica, pois é nesse momento que passa a coexistir uma nova realidade, no qual a mulher segue uma nova rotina e novos hábitos, além de adquirir novas responsabilidades. Desse modo, para um número significativo de mulheres, o puerpério é vivido como uma fase permeada por sentimentos e sensações agradáveis. O cuidado da mulher no pós-parto é fundamental para a saúde materna e neonatal e deve incluir o pai, a família em seus diversos arranjos e toda a rede social envolvida nesta fase do ciclo familiar, tendo em vista mudanças anatômicas e fisiológicas no organismo da mulher, embora questões de ordem psicossocial relacionadas à maternidade, à sexualidade, à autoestima, à reorganização da vida pessoal e familiar estejam ocorrendo concomitantemente e influenciem a passagem desse período.

\subsection{Sentimentos Positivos}

A chegada de um novo membro no convívio familiar gera modificações, pois, traz consigo a reformulação dos papéis e nas regras de funcionamento familiar. É salutar acrescer que o apoio dos familiares e, principalmente, do companheiro em situações de nascimento, interfere de forma positiva no cotidiano da puérpera. Assim, a presença do novo ser reflete no comportamento do casal. Isso leva a considerar o nascimento como fator de mudanças como e alterações na vivência familiar, cuja compreensão entre os pais, nesse momento, torna-se essencial, (Marciano \& Amaral, 2015).

Em conformidade com Mazzo; Brito \& Santos (2014), o modo como o homem entende a sua vivência no ciclo grávidopuerperal contribui para que ele exerça influências positivas na gravidez, parto, pós-parto e aleitamento materno. Nessa perspectiva, considera-se a importância de orientá-lo quanto ao seu direito de acompanhar sua companheira nas consultas prénatal, no momento do parto e pós-parto, favorecendo um maior vínculo dessa paternidade, proporcionando-lhe, assim, condições de entender as mudanças que acontecem nesse período.

Conforme os autores referidos acima, as alterações vividas pelas mulheres podem proporcionar crescimento pessoal ao perceberem a dependência da criança a elas. Diante disso, elas expressam senso de preocupação, responsabilidade e sentimentos de felicidade, como também satisfação por terem um objetivo de vida concretizado. Essas emoções tendem a estabelecer o vínculo mãe-bebê a partir do significado que o filho tem para ela. Na verdade, o nascimento de uma criança é um acontecimento passível de influenciar, de forma diversa, o equilíbrio eventualmente desfrutado por cada membro da família.

O nascimento de um filho, principalmente o primeiro, inaugura definitiva e concretamente a maternidade, e esse fato vem acompanhado de todo o status e toda a pressão social do papel de mãe. A mulher se vê obrigada a abandonar seu papel de filha e assumir o de mãe. Mas o parto também fornece à mulher a oportunidade de reviver seu próprio nascimento e de renascer como mulher, além de nascer como mãe. Na verdade, o parto é, por si só, um momento um evento de significância psicológica incontestável, e não apenas o meio pelo qual homens e mulheres se tornam pais (Marciano \& Amaral, 2015).

Estudos sobre a representação social da puérpera realizados em um Alojamento Conjunto por Ondino \& Guirardello (2010) mostrou que receber auxílio para o atendimento de suas necessidades básicas e para iniciar sua relação com seu filho representa segurança, tranquilidade e amparo para a mulher. Ainda, é possível constatar, nos estudos que avaliam a satisfação de forma geral, que os aspectos relacionados à comunicação e a confiança são muito valorizados pelas clientes femininas. 
Adicionalmente, enfatizam que as mulheres que relataram satisfação com o trabalho e nascimento foram aquelas que já tinham uma expectativa prévia sobre o seu desempenho no momento da parturição e também participaram de atividades educativas que as ajudaram a esclarecer quanto ao que esperar desse momento.

\subsection{Depressão pós-parto}

Para Freitas (2021), o pós-parto é um momento muito delicado, pois envolve o cuidado do bebê e as mudanças físicas e emocionais, no cotidiano e nas relações sociais. Deve-se dar especial atenção às condições psíquicas e sociais da mulher neste momento, pois uma das características marcantes desse período é a ansiedade despertada com a chegada do bebê, o que pode ocasionar sintomas depressivos. Trata-se, portanto, de uma fase em que as emoções, naturalmente, encontram-se alteradas e, os novos sentimentos que surgem se comporta de forma ambivalente, o que torna muito propício o surgimento de patologias emocionais que incluem a tristeza, a psicose puerperal, e a Depressão Pós-Parto.

A Depressão Pós-Parto (DPP), também conhecida como depressão puerperal, materna ou pós-natal, pode ser considerada como uma síndrome psiquiátrica que pode desencadear consequências ruins para a interação entre mãe e filho. Ainda assim, pode ser uma manifestação do sofrimento e da dor humana que atinge um número considerável de mulheres no mundo (Moura; Fernandes \& Apolinario, 2011; Mastellini \& Silva, 2012).

De forma resumida, o termo depressão pode ser utilizado para se referir a um estado afetivo habitual quando associado aos sentimentos de perda ao longo da vida do indivíduo, um sintoma, uma síndrome ou uma doença quando se estende às mudanças de humor, de pensamento, de atitudes que incapacita parcial ou total o indivíduo no desenvolvimento de suas atividades de vida diária (Aguiar, 2011).

De acordo com Hildebrandt (2013), esse fenômeno é considerado um problema importante de saúde pública de grande interesse dos pesquisadores. Ele ainda cita que a adoção de programas de detecção e tratamento da depressão puerperal foi descrita como fundamental para a agenda de saúde dos Estados Unidos. Enquanto isso, no Reino Unido, o suicídio foi registrado como a principal causa de morte materna da atualidade e, nesse país, cresce a quantidade de pesquisas e ações que envolvem essa temática.

Nesse contexto, o termo DPP ainda é um termo que carece de uma definição universalmente aceita, pois os sistemas classificatórios psiquiátricos da Associação Americana de Psiquiatria e da Organização Mundial de Saúde, não consideram os sintomas depressivos no pós-parto como uma entidade nosológica independente, sendo que estes sintomas não são considerados diferentes daqueles que ocorrem em outros momentos na vida das mulheres. No Brasil, a depressão chega tem risco de recorrência de $50 \%$ dos casos e chega próximo de 100\% em mulheres com algum histórico de transtorno de humor e DPP prévios (Pina \& Loures, 2014).

Segundo Hildebrandt (2013), a décima edição da Classificação Internacional de Doenças (CID-10) classifica a depressão pós-parto no código F53.0, que dita sobre “Transtornos Mentais e Comportamentais Associados ao Puerpério". Para tanto, os sintomas precisam manifestar-se nas primeiras seis semanas ou nas primeiras quatro a oito semanas, variável para cada autor, e ainda, não está enquadrado em critérios específicos de outros transtornos, ou seja, o seu diagnóstico acaba sendo confirmado por exclusão.

Para Aguiar (2011), o quadro de depressão pós-parto assemelha-se com a depressão. Os sintomas variam de acordo com a intensidade como que é manifestada, conforme a personalidade da puérpera, seu contexto de inserção socioeconômico e cultural, sua história de vida, predisposição natural, condições em que se desenvolve a gravidez, relacionamento com o parceiro, assim como, com os aspectos fisiológicos e das mudanças bioquímicas que se processam logo após o parto.

Em geral, a mulher sente uma tristeza profunda, com perda da autoestima, da motivação para a vida, de modo que, pode tornar incapacitante, sendo na maioria das vezes incapacitante. Surgem ainda manifestações clínicas como a irritabilidade, o 
choro frequente, sentimentos de desamparo e desesperança ou de culpa excessiva, falta de energia, desinteresse sexual, transtornos alimentares e do sono, a sensação de incapacidade em resolver novas situações, pensamentos suicidas, e rejeição ao bebê (Aguiar, 2011; Mastellini \& Silva, 2012).

De acordo com Mastellini \& Silva (2012), o Manual Diagnóstico e Estatístico de Transtornos Mentais (APA - American Psychiatric Association, 2002) defende que o diagnóstico da depressão puerperal é confirmado quando a mãe apresenta pelo menos cinco destes sintomas citados acima.

Os eventos desencadeantes desse agravo permanecem obscuros, contudo Costa (2013) afirma que alguns fatores podem contribuir para a sua manifestação, tais como a situação socioeconômica, a negação da gravidez, o grande número de gestações, de partos e de filhos vivos, o pequeno tempo de relacionamento com o companheiro, história de problemas obstétricos, o tempo para tocar no bebê após o nascimento, os conflitos domésticos, o escasso apoio do companheiro, o grande número de tarefas e a experiência conflituosa da maternidade. E como fatores biológicos são possíveis citar o histórico de transtorno do humor ou ansiedade e de transtorno disfórico pré-menstrual e histórico familiar de doenças psiquiátricas.

Considerando ainda as observações do autor citado acima, a maternidade em idade inferior a 16 anos, transtorno psiquiátrico pregresso, altas cargas de estresse nos últimos 12 meses, conflitos conjugais, estado civil de solteira ou divorciada, desemprego (puérpera ou seu cônjuge), ausência ou insuficiência de suporte social ou emocional, a personalidade desorganizada, o sexo do bebê (muitas vezes indesejado), as relações afetivas insatisfatórias e os abortamentos espontâneos ou de repetição. Vale ressaltar que a depressão materna não afeta apenas a saúde mental das mulheres, mas também dos cônjuges e filhos. As formas mais leves de depressão materna podem prejudicar a interação mãe-bebê e o desenvolvimento cognitivo das crianças.

De acordo com Mastellini \& Silva (2012), o Ministério da Saúde não publicou diretrizes para tratamento farmacológico da DPP, mas acredita-se que a psicoterapia é a principal indicada para auxiliar o tratamento. O uso de fármacos deve ser cauteloso em razão de todas as medicações psicotrópicas serem excretadas no leite materno em graus variados, sob risco de comprometer o crescimento e desenvolvimento da criança.

Para tanto, é importante reconhecer precocemente os fatores de risco para a depressão no ciclo gravídico-puerperal, bem como a vulnerabilidade biológica para os transtornos de humor no puerpério, como forma de traçar intervenções preventivas para os casos de suscetibilidade. As estratégias de intervenção, portanto, precisam garantir o apoio de outra mulher, o suporte emocional do companheiro, a detecção precoce da depressão, o suporte social, a intervenção multidisciplinar logo que os sintomas sejam detectados e um trabalho psicológico de prevenção no pré-natal (Winnicott, 2013).

Freitas (2021) reforça a ideia de que, na verdade, um número cada vez maior de estudos mostra que a psicoterapia ou aconselhamento é, em muitos casos, tudo que uma mulher precisa para conseguir sair da depressão e, em casos graves surte muito efeito. O tipo de terapia que uma mãe precisa depende, na maioria dos casos, da gravidade da depressão pós-parto. Em resumo, o tratamento indicado é finalizado quando os objetivos forem atingidos e o paciente souber lidar por si próprio com situações rotineiras, sendo capaz de reconhecer um pensamento negativo e modificá-lo. A possibilidade de recaída é possível, e o paciente deve ser alertado e instruído a identificar situações futuras que possam facilitar a um episódio depressivo.

\subsection{Tristeza Puerperal ou Baby Blues}

A tristeza puerperal, disforia puerperal ou baby blues, caracteriza-se como um tipo de depressão mais branda, ou ainda, um distúrbio transitório de humor que tem como marca a instabilidade emocional e o choro fácil, e atinge cerca de $70 \%$ a $90 \%$ das novas mães, entre o segundo e o quinto dia após o parto (Mastellini \& Silva, 2012; Fernandes \& Cotrin, 2013).

A disforia puerperal, segundo Freitas (2021) é considerada a forma mais leve dos quadros puerperais. Pode durar de uma a duas semanas após o parto, ou seja, a sintomatologia geralmente desaparece de modo espontâneo e os sintomas mais frequentes são, a labilidade emocional marcado pelo sentimento de tristeza, crises de choro, emotividade exacerbada, 
hipersensibilidade, ansiedade, agonia, fadiga e preocupações excessivas com a lactação e com a saúde do bebê, ou ainda, distúrbios cognitivos leves, a exemplo da dificuldade de concentração, raciocínio e problemas com a memória, porém, são manifestações que não chegam a impedir a realização de atividades diárias pela mãe.

Corroborando com este pensamento, Villela et al., (2016), ressaltam que a tristeza materna também chamado de blues do segundo, terceiro ou décimo dia, está quase provado que é causado pelas mudanças hormonais que se dão no corpo feminino imediatamente depois do nascimento, por alterações dos hormônios, especialmente baixos níveis de estrógeno e a progesterona ou uma disfunção nos hormônios tireoidianos). Normalmente há uma maior probabilidade das pessoas adoecerem emocionalmente durante os momentos mais críticos de suas vidas e por isso as chances de adoecimento nesta fase de sua vida são maiores do que em outras épocas.

Fernandes \& Cotrin (2013) colocam que esse agravo pode ser capaz de fazer com que a mãe recuse o contato das pessoas com quem convive, podendo se estender até ao seu bebê, do qual evita olhar em seus olhos, trocar a fralda, amamentar, acalentálo em seu colo. Aguiar (2011) ainda aponta que é imprescindível orientar e esclarecer que o baby blues pode evoluir para um quadro de depressão pós-parto, a depender da gravidade de cada caso. A DPP, diferentemente, se manifesta com características mais severas e intensas, apesar de, no início de todos os agravos puerperais existirem sintomatologia semelhante. Desse modo, a diferenciação é feita posteriormente, pela manutenção e intensidade dos sintomas, para além das duas semanas preconizadas para o blues puerperal.

O Quadro 1 faz uma diferenciação entre a Tristeza e a Depressão Puerperal.

Quadro 1 - Diferenças entre Tristeza e Depressão Puerperal.

\begin{tabular}{|c|c|c|}
\hline & $\begin{array}{l}\text { TRISTEZA } \\
\text { PUERPERAL }\end{array}$ & $\begin{array}{l}\text { DEPRESSÃO } \\
\text { PUERPERAL }\end{array}$ \\
\hline CONCEITO & $\begin{array}{l}\text { Distúrbio psiquico } \\
\text { leve e transitório }\end{array}$ & $\begin{array}{l}\text { Transtorno psiquico de } \\
\text { moderado a severo com } \\
\text { inicio insidioso }\end{array}$ \\
\hline PREVALÊNCIA & 50 a $80 \%$ & 10 a $15 \%$ \\
\hline MANIFESTAÇĀO & $\begin{array}{l}\text { Inicia-se no } 3^{\circ} \text { até o } \\
4^{\circ} \text { dia do puerpério }\end{array}$ & $\begin{array}{l}\text { Inicio insidioso na } 2^{a} \text { a } 3^{a} \\
\text { semana do puerpério }\end{array}$ \\
\hline SINTOMAS & $\begin{array}{c}\text { Choro, flutuação de } \\
\text { humor, irritabilidade, } \\
\text { fadiga, tristeza, } \\
\text { insônia, dificuldade } \\
\text { de concentração, } \\
\text { ansiedade relacionada } \\
\text { ao bebê. } \\
\end{array}$ & $\begin{array}{l}\text { Tristeza, choro fäcil, } \\
\text { desalento, abatimento, } \\
\text { labilidade, anorexia, } \\
\text { náuseas, distúrbios de } \\
\text { sono, insônia inicial e } \\
\text { pesadelo, idéias suicidas, } \\
\text { perda do interesse sexual. }\end{array}$ \\
\hline $\begin{array}{c}\text { CURSO E } \\
\text { PROGNÓSTICO }\end{array}$ & $\begin{array}{c}\text { Remissão espontânea } \\
\text { de uma semana a dez } \\
\text { dias }\end{array}$ & $\begin{array}{l}\text { Desenvolve-se lentamente } \\
\text { em semanas ou meses, } \\
\text { atingindo assim um limiar; } \\
\text { o prognóstico está } \\
\text { intimamente ligado } \\
\text { diagnóstico precoce e } \\
\text { intervenções adequadas. }\end{array}$ \\
\hline TRATAMENTO & $\begin{array}{c}\text { Psicoterapia } \\
\text { enfatizando a } \\
\text { educação e o } \\
\text { equilibrio emocional } \\
\text { da puérpera. }\end{array}$ & $\begin{array}{c}\text { Psicoterapia, } \\
\text { farmacologia. } \\
\text { Eletroconvulsoterapia } \\
\text { (casos especiais) }\end{array}$ \\
\hline
\end{tabular}

Fonte: Fernandes \& Cotrin (2013).

De acordo com Aguiar (2011), é muito importante identificar as mulheres que apresentam baby blue, pelo risco aumentado que elas têm de desenvolver quadros depressivos piores ainda no primeiro ano do pós-parto. Os fatores de risco mais comum incluem: antecedentes de depressão ou bipolaridade, disforia pré-menstrual, antecedentes familiares para depressão ou bipolaridade, história pregressa de estressores recentes, contexto socioeconômico e cultural no qual está inserida, antecedentes 
de depressão ou ansiedade na gravidez, ideias pessimistas em relação às circunstâncias relacionadas à gravidez, ambivalência em relação à gravidez, entre outras dificuldades emocionais. Essa frequência aponta para esse fenômeno como algo comum, evolutivo e adaptativo a novas tarefas e novas relações para a mulher.

Além disso, algo que conta nesse momento, depois da mãe dá à luz ao bebê, é a representação do final de sua gravidez psíquica, no qual a mãe deixa de se relacionar com o bebê no espaço intrauterino para se permitir entrar num sistema interativo com o neonato. Nesses casos, a abordagem feita à mulher com tristeza puerperal ou suscetível a adquirir esse tipo de problema puerperal é o fornecimento de suporte emocional adequado, compreensão e auxílio nos cuidados com o bebê.

\subsection{Psicoses Puerperais}

De acordo com Mastellini \& Silva (2012), a psicose pós-parto caracteriza-se como o transtorno mental mais grave que pode surgir no puerpério. É uma doença mental muito séria Sua prevalência está em torno de 0,1\% a 0,2\%, sendo maior do que essas porcentagens em mulheres bipolares. Geralmente, tem início rápido, podendo surgir sinais e sintomas, entre os primeiros dias até duas semanas do pós-parto como euforia, humor irritável, compulsão para falar, agitação, insônia, delírios, mania de perseguição, alucinações e comportamento desorganizado, desorientação, confusão mental, perplexidade e despersonalização podendo perder o contato a realidade.

A condição é, no entanto, muito grave, e pode ser perigosa para mães e bebês. Porque mulheres com psicoses pós-parto perdem sua conexão com a realidade, suicídio e violência podem tornar-se possibilidades. Reconhecer os sinais o mais rapidamente possível é importante para o tratamento precoce e eficaz (Villela et al., (2016).

Em conformidade com os autores supracitados, argumentam que ocasionalmente, alguns dos sintomas da psicose pósparto podem ser causados por condições médicas subjacentes: uma infecção grave, uma febre muito alta ou um problema neurológico, por exemplo. Um profissional médico deve avali9ar os sintomas e realizar testes, geralmente incluindo o exame de sangue básico, para descartar possíveis problemas médicos. Muitas mulheres com psicose pós-parto precisam ser hospitalizadas para que a equipe médica possa monitorá-la até se estabilizar

Esse tipo de sentimento pós-parto apresenta-se como uma situação de risco para a ocorrência do infanticídio (assassinato da criança), quando existem ideias delirantes envolvendo o bebê, a exemplo de que ele tenha algum defeito (malformação) ou esteja morrendo, ou ainda, que ele tem poderes especiais, assemelha-se a um deus ou a um demônio (Mastellini \& Silva, 2012).

Este fenômeno ocorre no período pós-parto, em mulheres já predispostas a certa anormalidade. O que ocorre é que as manifestações psicopatológicas já existentes encontram no puerpério condições favoráveis para sua instalação. As reações normais que a gestação e o parto geram na mulher já predisposta a alguma perturbação psíquica se associam e podem acarretar um surto ou episódio psicótico. Além disso, pode-se afirmar que apesar de a psicose ser um transtorno que não possui uma única definição de causa, ela tem alguns fatores anteriores ao diagnóstico que costumam explicar o desencadeamento da doença, principalmente nos casos ligados a questões de relacionamento entre um ser humano e outro (Alves et al., 2021).

Nesse contexto, o autor referido acima expõe que a organização psíquica de algumas pessoas pode facilitar o desenvolvimento da psicose. Conforme o autor, mulheres com imaturidade psíquica no mundo relacional, que tenham um grau de dependência muito elevado quando envolvidos em uma relação e que tenham dificuldade de distinguir a si mesmas do outro podem fazer parte desse grupo.

A etapa correspondente ao pós-parto pode causar uma psicose puerperal na qual, o transtorno mental, de natureza patológica elimina por completo a capacidade de discernimento e entendimento da mulher, podendo levá-la a cometer o ato de atacar a si mesma ou ao seu filho, dependendo do conteúdo de seu sistema delirante e grau de agitação. É necessária a intervenção dos familiares e do psiquiatra assim que se perceba alguma atitude diferenciada em relação ao bebê, para que se evitem danos mais graves. Um bom prognóstico está relacionado com um bom funcionamento pré-mórbido e suporte familiar (Villela et al., 
2016).

Prosseguindo com as considerações do autor acima citado, é preciso haver uma relação de causalidade entre o estado puerperal e o ato de infanticídio, já que nem sempre o puerpério causa perturbações psíquicas na mulher. Deverá ficar evidente que há diminuição da capacidade de entendimento oriundo de uma confusão mental puerperal para que seja então prescrito o crime de infanticídio; caso contrário, o que se tem é a ação de um homicídio.

Mastellini \& Silva (2012), procuram apontar os fatores de risco mais frequentes para o desenvolvimento da psicose puerperal: a primiparidade, complicações obstétricas e antecedentes pessoais ou familiares de transtornos psiquiátricos, sobretudo outros transtornos psicóticos. Geralmente, esses casos requerem tratamento intensivo e até mesmo hospitalização nas duas primeiras semanas após o parto. Estima-se que 20\% têm remissão completa do quadro e não apresentam recorrências, mas a repetição de novo episódio de psicose pós-parto pode acontecer em 18\% a 37\% das mulheres, e as chances de existir episódio de transtorno psicótico ou afetivo subsequente ao pós-parto, chega a acertar 38\% a $81 \%$ das mulheres.

Strapasson \& Nedel, (2010) relatam que a busca por auxílio familiar é evidente, bem como a percepção sobre o quanto este é importante no período do puerpério imediato, fazendo com que se sinta mais segura e tranquila, sabendo que tem com quem contar neste período de adaptação. $\mathrm{O}$ apoio familiar apresenta-se como benefício e estratégia no auxílio para a puérpera na superação das adversidades do cuidado com o recém-nascido, favorecendo o desenvolvimento de sua própria competência e possibilidades de amadurecimento, desenvolvendo segurança frente ao papel da maternidade.

Em alguns casos, recorrer à ajuda psicológica se faz necessário para que está grávida possa entender melhor o que está acontecendo e elaborar conteúdos emocionais vividos por ela: alguém que a escute e ajude a perceber, nomear e tomar consciência daquilo que está obscuro e impedindo de viver este momento tão singular e especial. Afinal, cada mulher é única em suas experiências na gestação e ao longo da maternidade.

\section{Considerações Finais}

A partir dos pressupostos apresentados neste estudo, pode-se pensar que no decorrer que no período puerperal a mulher passa por diferentes mudanças, que interferem em seu mundo intrapsíquico e relacional. Altera-se significativamente a visão que ela tem de si mesma e de sua relação com o mundo. Sentimentos estes em relação, às transformações físicas e emocionais refletindo na sua percepção de que já não são as mesmas, de que agora a sua função no mundo mudou.

A mulher atual vê-se encurralada entre aspectos de sua subjetividade, entendida aqui como construída social e historicamente, em que vemos fortes oposições entre necessidade de realização pessoal, aquilo que é socialmente aceito ou adequado e a crescente necessidade de formação acadêmica. Essas funções determinam, portanto, papéis sociais que necessitam ser conciliados no cotidiano dessas mulheres. Tal conciliação remete a um desafio diário, na medida em que a associação de diversas frentes de ação traz desgaste substancial, decorrente da rotina intensa de atividades que lhes são impostas.

O estudo possibilitou verificar que as mulheres vivenciam uma série de mudanças no período do puerpério, desde a considerável diminuição das horas de sono, até a perda de sua autonomia, uma vez que toda a sua rotina é controlada de acordo com os horários do bebê. Esse período traz uma série de sentimentos novos, que passam a participar de suas tomadas de decisão, daquele momento em diante.

Por outro lado, percebemos a transição dos sentimentos inicialmente negativos para os de alegria e satisfação com os sentimentos positivos relacionados ao bebê. Disto se depreende a ideia de que o processo gestatório, desde a sua descoberta até o nascimento, envolve um cenário complexo em torno do qual gravitam aspectos como o apoio social da família, companheiro e profissionais de saúde, sentimentos de ambivalência e preocupações. Neste âmbito, todos os esforços devem ser envidados para que a mesma supere as dificuldades impostas pelo período e ganhe satisfação com a maternidade. 
Esse estudo apresentou como relevância o conhecimento sobre a vivência da mulher contemporânea diante da maternidade e como ela passa a definir a sua representação, pois foi constatado que apesar de tantos papeis importantes na sociedade, além de ser mãe, a maternidade continua sendo para a mulher um acontecimento de elevada importância em sua vida.

Diante dos resultados obtidos, deixamos como possíveis desdobramentos estudos que envolvam o aprofundado sobre o acolhimento das necessidades maternais que dizem respeito às questões psicológicas e sociais. Além da importância do papel da família e o apoio que esta oferece em diferentes momentos aos indivíduos.

\section{Referências}

Aguiar, D. T. (2011). Quando ser mãe dói: história de vida e sofrimento psíquico no puerpério. Dissertação de Mestrado (Cuidados Clínicos em Saúde), Universidade Estadual do Ceará, Fortaleza.

Alves, A. C. P., Lovadini, V. L., \& Sakamoto, S. R. (2021). Sentimentos vivenciados pela mulher durante o puerpério. Rev Enferm Atual In Derme, 95(33), 112.

Amorim, S. P. T. (2010). Tristeza pós-parto: A importância do diagnóstico precoce. Trabalho de Conclusão de Curso (Licenciada em Enfermagem), Universidade Fernando Pessoa, Ponte Lima.

Costa, L. M. (2013). Depressão pós-parto. Trabalho de Conclusão de Curso (Especialização em Saúde Coletiva e da Família), Faculdade de Odontologia de Piracicaba, Universidade Estadual de Campinas, Piracicaba.

Dias, E. O. (2014). A teoria do amadurecimento emocional. $3^{\circ}$ Ed. São Paulo: DWW.

Fernandes, F. C., \& Cotrin, J. T. D. (2013). Depressão pós-parto e suas implicações no desenvolvimento infantil. Revista Panorâmica [On-Line], 14(1), 15-34. Freitas, B. K. P. S. de. (2021). Humanização da Assistência no processo parturitivo: Instruindo mulheres em uma maternidade escola do Rio Grande do Norte. Dissertação de Mestrado (Pós-Graduação em Saúde e Sociedade), Universidade Federal do Rio Grande do Norte.

Gonçalves, J. 2012). Depressão pós-parto e retraimento social do bebé. Braga. 2 ed. Porto Editora.

Hildebrandt, F. M. P. (2013). Depressão Pós-parto: Aspectos epidemiológicos e proposta de tratamento cognitivo-comportamental. Tese de Doutorado (Programa de Pós-Graduação em Psicologia), Universidade Federal do Rio de Janeiro - UFRJ, Rio de Janeiro.

Jericó, E. C., \& Teixeira, J. (2012). A Relação Neuropsicológica Mãe-Bebê na Depressão Pós-Parto. Artigos de Psicologia. Revista Neuropsicológia, 08(3), 2235 .

Lermen, J. K. (2010). Vinculo conjugal e a depressão Pós-parto: Antes e depois da Psicoterapia Breve Pais-Bebê. Trabalho de Conclusão de Curso (Curso de especialização em Psicologia Clínica), Universidade Federal do Rio Grande do Sul, Porto Alegre.

Lopes, R. C.S., Prochnow, L. P., \& Piccinini, C. A. (2010). A relação da mãe com suas figuras de apoio femininas e os sentimentos em relação à maternidade. Psicologia em estudo, 15(2). Abr./Jun.

Marciano, R. P., \& Amaral, W. N. (2015). O vínculo mãe-bebê da gestação ao pós-parto: uma revisão sistemática de artigos empíricos publicados na língua portuguesa. Femina, 43(4), 155-159.

Mastellini, H. F. Z., \& Silva, K. R. S. (2012). Depressão pós parto: Uma questão de saúde pública. Trabalho de Conclusão de Curso (Especialização em Saúde Coletiva e Saúde da Família), Centro Universitário Filadélfia, Londrina.

Mazzo, M. H. S. N., Brito, R. S. de., \& Santos, F. A. P. S. dos. (2014). Atividades do enfermeiro durante a visita domiciliar pós-parto. Rev enferm UERJ, Rio de Janeiro, 22(5), 663-667.

Mendes, K. D. S., Silveira, R. C. C. P., Galvão, C. M. (2008). Revisão integrativa: método de pesquisa para a incorporação de evidências na saúde e na enfermagem. Texto Contexto Enferm., 17(4), 758-764.

Moraes, L. L. (2010). Maternidade: o sonho de toda mulher? VIII Congresso Ibero-americano de Ciência, Tecnologia e Gênero.

Moreira, D. (2015). Cuidados na Saúde Materna. Plataforma online com trabalhos da formação base e tecnológica de Técnico Auxiliar de Saúde. Curso Técnico de Agente em Geriatria.

Moura, E. C. C., Fernandes, M. A., \& Apolinario, F. I. R. (2011). Percepção materna sobre transtornos psiquiátricos no puerpério: implicações na relação mãefilho. Rev. Bras. Enferm., Brasília, 64(3), 445-450.

Pina, L. N. de S., \& Loures, M. C. (2014). Puérpera com Depressão Pós-Parto: a influência na relação com o bebê. EVS estudos, Goiânia, 41 (2), 341 -357.

Ryung; K. H., Munhoz, C., Motta, I., Simon, R., Yamamoto, K., \& Mello, M. L. (2011). Estudo Sobre Depressão Pós-Parto: A Importância do Ambiente. Departamento de Obstetrícia do Hospital Universitário da USP. São Paulo.

Siqueira, D. A., Rolim, M. A. D., Ferreira Junior, A. R., Rocha, F. A. A., \& Cavalcante, M. M. B. (2017). Sentimentos e conhecimentos de puérperas em face da sífilis congênita neonatal. Rev. Bras. Pesq. Saúde, Vitória, 19(3), 56-61. 
Research, Society and Development, v. 11, n. 1, e2011123206, 2022

(CC BY 4.0) | ISSN 2525-3409 | DOI: http://dx.doi.org/10.33448/rsd-v11i1.23206

Sobreira, N. A. S., \& Pessôa, C. G. de O. (2012). Assistência de enfermagem na detecção da depressão Pós-parto. Revista Enfermagem Integrada - Ipatinga: Unileste - MG - 5(1).

Tolentino, E. C., Maximino, D. A. F. M., \& Souto, C. G. V. (2016). Depressão pós-parto: conhecimento sobre os sinais e sintomas em puérperas. Rev. Ciênc. Saúde Nova Esperança, 14(1), 59-66.

Villela, J. P., Silva, I. de S. R. da., Martins, E. R. C., Ramos, R. C. de A., Costa, C. M. A., \& Spindola, T. (2016). Episiotomia: sentimentos vivenciados pelas puérperas. Rev enferm UERJ, Rio de Janeiro, 24(5).

Winnicott, D. W. (2013). Os bebês e suas mães. São Paulo: WMF Martins. 